\title{
Blood Zinc Level in Benha Children with Lower Respiratory Tract Infections
} A.M.Shaheen ${ }^{1}$, S.M.Fayed ${ }^{2}$, A.A.Sobeh ${ }^{3}$ and A.S.Kamel

${ }^{1}$ Pediatrics Dept., Faculty of Medicine, Benha Univ., Benha, Egypt ${ }^{2}$ Clinical Pathology Dept., Faculty of Medicine, Benha Univ., Benha, Egypt

${ }^{3}$ Pediatrics Dept., Faculty of Medicine, Benha Univ., Benha, Egypt

${ }^{4}$ (M.B.B.CH), Faculty of Medicine, Benha Univ., Benha, Egypt E-Mail:amany@gmail.com

\begin{abstract}
Lower Respiratory Tract Infections (LRTI) incorporates all diseases of the lungs and the aviation routes beneath the larynx and incorporates croup conditions, bronchitis, bronchiolitis and pneumonia. Zinc has a major part in cell digestion, with significant consequences for the safe framework and the intestinal mucosa. The targets of this investigation were to look at the blood zinc levels in kids hospitalized with lower respiratory diseases with those of controls. This investigation is cross sectional examination in which we considered 150 Egyptian kids. 100 patients determined to have lower respiratory lot diseases and 50 of evidently sound Egyptian youngsters age and sex coordinated as control. This examination was done at benha showing medical clinic and benha college emergency clinic in the time frame from March 2019 to December 2019 and all information about these patients were overhauled from the documents. Every one of our patients exposed to the accompanying: Full history taking and positive history information will be thought of. Full clinical assessment and positive information in assessment were thought of. Examinations: CBC, CRP, Chest X Ray and Blood Zinc Level. There were measurably critical abatement in Zinc among Cases than Controls gathering. There was genuinely huge negative connection among's Zinc and RD grades. The kids with LRI had lower serum zinc levels than the control. There is a negative relationship between's serum zinc level and the evaluation of respiratory pain among kids with LRI.
\end{abstract}

Keywords: Lower Respiratory Tract Infections- Zinc , Evaluation.Corresponding.

\section{Introduction}

Intense lower respiratory plot contaminations (ALRTIs) in kids more youthful than 5 years are the primary driver of youth dismalness and mortality worldwide and address practically $60 \%$ of hospitalizations inferable from baby irresistible infection [1].

Bronchitis, bronchiolitis, and pneumonia alone or in blends comprise types of lower respiratory plot contaminations (LRTIs) [2].

The opportunity to create LRTI might be improved by wholesome factors, for example, zinc, iron, nutrient An and others, which are firmly identified with the body's protection from contamination. Decline in such supplements might be a danger factor for improvement of disease. Nonetheless, there are discussions with respect to the part of supplements particularly iron in respiratory lot contaminations in youth [3].

Zinc is a fundamental cancer prevention agent mineral that is associated with various parts of cell digestion. A powerful cell reinforcement can act against irritation and forestall the subsequent tissue injury [4].

Zinc inadequate youngsters are at expanded danger of confined development, creating diarrheal sicknesses and respiratory parcel contaminations. It is thought to diminish weakness to ALRTI by directing different invulnerable capacities including ensuring the wellbeing and honesty of respiratory cells during lung irritation and injury. Supplementation of zinc could decrease the danger of pneumonia and the danger and term of looseness of the bowels, diarrhea and jungle fever passings among every irresistible sickness, and they represented 3.9 million passings around the world [5].

Zinc insufficiency diminishes the capacity of the body to react to disease and furthermore antagonistically influences both cell-interceded and humeral insusceptible reactions. It has a crucial job in cell digestion, with significant consequences for the insusceptible framework and the intestinal mucosa [6].

Zinc is the second most plentiful metal in life forms, second just to Iron, with 2-4 gram disseminated all through the human body. It is basic for cell development, advancement and separation. Zinc is in each cell of the human body and is needed for typical working. Zinc empowers many compounds to work, encourages protein combination, and controls cycles, for example, quality articulation and apoptosis. Zinc is associated with both vague and explicit insusceptible framework measures, including phagocytosis, support of gastrointestinal and respiratory plot linings, and improvement and capacity of $\mathrm{T}$ and $\mathrm{B}$ cells [7].

This investigation expected to think about the blood zinc levels in youngsters hospitalized with lower respiratory diseases with those of controls.

\section{Patients and methods Patients}

This study is cross sectional study in which we studied 150 Egyptian children. 100 patients diagnosed with lower respiratory tract infections and 50 of apparently healthy Egyptian children age and sex matched as control. This study was carried out at benha teaching hospital and benha university hospital in the period from March 2019 to December 2019 and all data about these patients were revised from the files.

\subsection{Inclusion criteria}

Children between 2 months and 12 years old hospitalized with lower respiratory tract infections 


\subsection{Exclusion criteria}

- Children with associated clinical diagnosis of diarrhea, allergic diseases or asthma in the preceding one month.

- Children with known zinc supplementation intake in the past onemonth prior to admission for current illness.

\section{Methods}

All our patients subjected to the following:

- Full history taking and positive history data will be considered

- Full clinical examination and positive data in examination were considered

- Investigations: CBC, CRP, Chest X Ray and Blood Zinc Level

\subsection{Serum zinc estimation}

Blood samples $(2 \mathrm{ml})$ were taken from the patients under complete aseptic conditions using wide-bore needle and withdrawn slowly from antecubital vein to avoid hemolysis of RBCs by careful venipuncture. These samples were to a dry tube, allowed to be clotted for 30 minutes, and then separated by centrifugation at $4000 \mathrm{rpm}$ for 5 minutes.

\section{Principle}

Zinc present in the sample is chelated by Zinc on the reagent at alkaline $\mathrm{PH}$. The formation of this complex is measured at a wavelength of $610 \mathrm{~nm}$.

\subsection{Ethical consideration}

Approval of the study by an ethical committee of Benha University, were obtained and informed consent was obtained from the parents before enrollment in the study.

\subsection{Statistical analysis}

The data were coded, entered and processed on computer using Statistical package for social science (SPSS) (version 24).The results were represented in tabular and diagrammatic forms then interpreted. Mean, standard deviation, range, frequency, and percentage were use as descriptive statistics. The following test was done: Chi-Square test $\mathrm{X}^{2}$ was used to test the association variables for categorical data. Student's t-test was used to assess the statistical significance of the difference between two population means in a study involving independent samples. Pearson's Product correlation coefficient: it evaluates the linear association between 2 quantitative variables ( one is the independent var.X, and the other is the dependent var., Y). value of " $\mathrm{r}$ " ranges from -1 to 1 . $\mathrm{P}$ value was considered significant as the following: $* \mathrm{P} \leq 0.05$ : Significant

\section{Results}

There was no statistically significant difference between cases group and control group regarding Age (month) and Sex Table (1).

Table (2) and figure (1) show that there were statistically significant decrease in Zinc among Cases than Controls group.

Table (3) show there were statistically significant positive correlation between Zinc and (Weight (kg), TLC , L, N, HB, HCT, PLT, CRP), there was statistically significant negative correlation between Zinc and CRP, RD grades, while there was no statistically significant difference between Zinc and other numerical data

There were statistically significant increase in Zinc among Grade I RD than II RD and III RD. There were statistically significant increase in Zinc among Grade II RD than III RD Table (4).

Table (1) Comparison between cases group and control group regarding demographic data.

\begin{tabular}{ccccccc}
\hline & & Cases group & Controls group & t. test & P. value \\
\hline $\begin{array}{c}\text { Age } \\
\text { (month) }\end{array}$ & \multirow{2}{*}{ Mean \pm SD } & & $19.48 \pm 27.45$ & $24.80 \pm 16.84$ & $-1.256-$ & 0.211 \\
& & No. & 47 & 18 & & \\
\multirow{2}{*}{ Sex } & female & $\%$ & $47.0 \%$ & $36.0 \%$ & $X^{2}$ & 0.200 \\
& & No. & 53 & $64.0 \%$ & 1.643 & \\
\hline
\end{tabular}

Table (2) Comparison between cases group and control group regarding Zinc.

\begin{tabular}{lccccc}
\hline & & Cases group & Controls group & t. test & P. value \\
\hline Zinc & Mean \pm SD & $51.31 \pm 13.03$ & $90.25 \pm 3.06$ & $-20.807-$ & .000 \\
\hline
\end{tabular}

Table (3) Correlation between Zinc and other numerical variables.

\begin{tabular}{lcc}
\hline \multirow{2}{*}{ Correlation } & \multicolumn{2}{c}{ Pearson's correlation } \\
\cline { 2 - 3 } & $\mathbf{r}$ & $\mathbf{p}$ \\
\hline Age (month) * Zinc & 0.071 & 0.054 \\
Weight $(\mathbf{k g}) *$ Zinc & 0.062 & 0.000 \\
TLC * Zinc & 0.050 & 0.000
\end{tabular}


Table (3) Continue

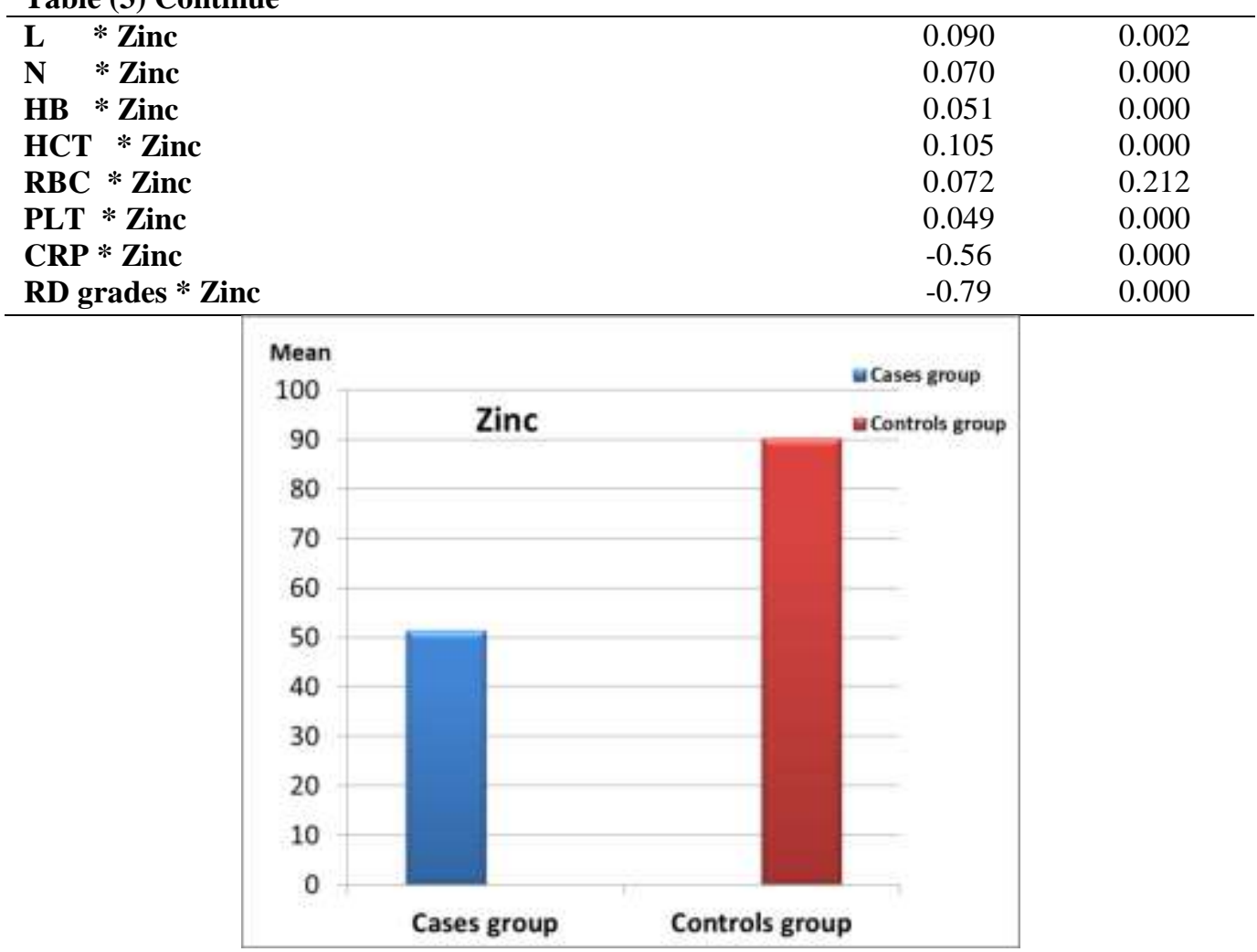

Fig (1) Comparison between cases group and control group regarding Zinc.

Table (4) correlation between Respiratory distress grade and Zinc.

\begin{tabular}{|c|c|c|c|c|c|c|c|}
\hline & & \multicolumn{3}{|c|}{ Respiratory distress grade } & \multirow[b]{2}{*}{ F. test } & \multirow{2}{*}{$\begin{array}{c}\text { P. } \\
\text { value }\end{array}$} & \\
\hline & & Grade I RD & Grade II RD & $\begin{array}{c}\text { Grade III } \\
\text { RD }\end{array}$ & & & \\
\hline \multirow[b]{2}{*}{ Zinc } & Rang & $65.0-79.0$ & $39.0-61.0$ & $28.0-40.1$ & \multirow[t]{2}{*}{231.55} & \multirow[t]{2}{*}{.000} & $\mathrm{P} 1=0.000$ \\
\hline & Mean \pm SD & $70.00 \pm 3.32$ & $49.55 \pm 4.95$ & $31.94 \pm 3.25$ & & & $\begin{array}{l}\mathrm{P} 2=0.000 \\
\mathrm{P} 3=0.000\end{array}$ \\
\hline
\end{tabular}

P1-- $\rightarrow$ between Grade I RD and Grade II RD

P2- $\rightarrow$ between Grade I RD and Grade III RD

P3 $-\rightarrow$ between Grade II RD and Grade III RD

\section{Discussion}

This examination demonstrated that, there was no measurably critical diverse among patients and controls with respect to segment information ( $p>0.05$ ).

This investigation indicated that, the mean time of cases was (19.48 \pm 27.45 months).

This concurred with Shaheen et al., [6] who announced that the mean age was ( $22 \pm 17$ months).

This outcome was higher than results found in examinations embraced in Uganda Nepal [8]. They detailed that the mean age of their youngsters was (17.9 \pm 12.2 months);

The mean age of our patients was lower than that detailed by Shah et al. [9] in their cases (108 \pm 60 months). This distinction found in the considered patients might be because of a wide variety in the causative living beings.
This investigation demonstrated that, male (53\%) patients more than females. There is a male transcendence.

These outcomes were in concurrence with Rady et al., [10] who saw that male patients were influenced by lower respiratory contaminations more than females, which outline our social inclination.

This investigation indicated that, there were genuinely critical lessening in Zinc among Cases than Controls gathering

This concurred with Shaheen et al., [6] who discovered there was profoundly measurable critical distinction between all patients and control bunches as respect serum zinc level (mean of serum zinc level in patients and control bunches were $56.413 \pm 29.474$ and $90.135 \pm 17.345$ individually, $\mathrm{p}=<0.0001$ ). 
This concurred with Kumar et al., [11] who discovered mean zinc level in cases was $54.84 \pm 18.31$ and in controls was $76.84 \pm 15.2$, which was measurably huge $(\mathrm{p}=0.000)$.

In our examination, there was genuinely huge negative connection among's Zinc and RD grades.

This concurred with Rady et al., [10] who found that, there was a negative connection between's low serum zinc level and the helplessness to diseases chiefly respiratory contaminations and the evaluation of respiratory trouble.

This was like outcomes found by Shakur et al., [12] and Kumar et al., [13].

In our examination, there was genuinely critical positive connection among's Zinc and weight.

This concurred with Rady et al., [10] who found that, who discovered there was measurably huge positive relationship between's serum zinc levels and weight.

\section{Conclusion}

The youngsters with LRI had lower serum zinc levels than the control and the pervasiveness of low serum zinc status in kids with LRI is high. In this manner, there is a need to decide if hospitalized youngsters oversaw for ALRI may profit by zinc supplementation as an aide to treatment just as post release. Since there was measurably huge negative connection among's Zinc and $\mathrm{RD}$ grades thus, we inferred that lower serum zinc levels were identified with more basic cases. There is a negative relationship between's serum zinc level and the evaluation of respiratory pain among kids with LRI.

\section{References}

[1] O.G.Behairy, O.I.Mohammad, O.S.Elshaer. Irondeficiency anemia as a risk factor for acute lower respiratory tract infections in children younger than 5 years. Egypt J Bronchol, Vol.12,PP. 352-357 ,2018.

[2] W.G.Barson, S.L.Kaplan, M.M.Torchia. Epidemiology, pathogenesis, and etiology of pneumonia in children. Available at:http://www.Up To Date , Vol.8,PP.78-99. 2016

[3] X.F.Zuo, J.X.Li, W.D.Zhou. The nutrient status of Chinese infants with pneumonia. Biomed Res, Vol.25,PP.317-320,2014.
[4] M.Aida, E.Ekramy. Serum zinc level in bronchial asthma. Egyptian Journal of Chest Diseases and Tuberculosis, Vol.66,PP.1,2017.

[5] A.Hussain, P,Saldanha, D.Sharma, A.Pandita, M.Yachha,

M.Tariq. Estimation of zinc levels in children with lower respiratory tract infections: a prospective observational study from India. Pediatric, Neonatal Nurse OpenJ, Vol.2(3),PP.91-98,2016.

[6] M.Shaheen, H.Aly, N.Esmael. Serum Zinc Level in Children with Acute Lower Respiratory Tract Infection. The Egyptian Journal of Hospital Medicine, Vol.72(1),PP.3835-3838,2018.

[7] G.singh, A.k.bhardwaj, G.chauhan, V.singh. Evaluation of serum zinc levels in hospitalized children with acute respiratory infections. Journal of biomedical and pharmaceutical research, Vol.8(6),PP.77-80,2019.

[8] M.Srinivasan, G.Ndeezi, C.Mboijana, S.Kiguli, S.Bimenya, V.Nankabirwa, J. Tumwine. Zinc adjunct therapy reduces case fatality in severe childhood pneumonia: a randomized double blind placebo-controlled trial. BMC Medicine, Vol.10,PP.14-24,2012.

[9] G.S.Shah, A.K. Dutta, D. Shah, O.P. Mishra. Role of zinc in severe pneumonia: a randomized double bind placebo controlled study, Italian J. Pediatr, Vol.38,PP.36-42,2012.

[10] H.I.Rady, W.A.Rabie, H.A.Rasslan, A.A.El Ayadi. Blood zinc levels in children hospitalized with pneumonia: a cross sectional study. Egyptian Journal of Chest Diseases and Tuberculosis. Oct 1, Vol.62(4),PP.697- 700,2013.

[11] D.E.Kumar, T.Annamalai, S.M.Ahmed, S.Sundari. Plasma zinc levels in normal and malnourished children with lower respiratory tract infection from 2 months to 5 years of age. Int $\mathrm{J}$ Contemp Pediatr, Vol.6,PP.1285-8, 2019.

[12] M.S.Shakur, M.A.Malek, N.Bano, K.Islam, Zinc status in well nourished Bangladeshi children suffering from acute lower respiratory infection, Indian Pediatr, Vol.41,PP.478-481,2004.

[13] S.Kumar, S.Awasthi, A.Jain, R.C.Srivastava. Blood zinc levels in children hospitalized with severe pneumonia: a case control study. Ind Pediatr, Vol.41(5),PP.486-92,2004. 